Orbis Tertius, vol. XXVI, nº 34, e210, noviembre 2021 - abril 2022. ISSN 1851-7811

Universidad Nacional de La Plata

Facultad de Humanidades y Ciencias de la Educación

Centro de Estudios de Teoría y Crítica Literaria

\title{
Hermetismo, negatividad y compromiso en la poesía de Aldo Oliva
}

\author{
Hermetism, negativity and commitment in Aldo Oliva's poetry
}

\author{
Bruno Crisorio \\ bruno.crisorio@gmail.com \\ Instituto de Investigaciones en Humanidades y \\ Ciencias Sociales (Universidad Nacional de La Plata) / \\ CONICET, Argentina
}

Recepción: 30 Marzo 2021

Aprobación: 17 Junio 2021

Publicación: 01 Noviembre 2021

Cita sugerida: Crisorio, B. (2021). Hermetismo, negatividad y compromiso en la poesía de Aldo Oliva. Orbis Tertius, 26(34), e210. https://doi.org/10.24215/18517811e210

\begin{abstract}
Resumen: Para George Steiner la literatura moderna está atravesada por una ruptura que él conceptualiza bajo el nombre de "palabra faltante": en un contexto de masificación y degradación de la palabra escrita (debido a la alfabetización creciente y a la proliferación de diarios y revistas), el poeta se encierra en su torre de marfil y se autoinstituye como alquimista literario, guardián de la lengua pura, custodio de lo inefable. Esta figuración del poeta y de su métier ha tenido diversas consecuencias a lo largo del siglo $\mathrm{XX}$, y es bajo esta estela que nos proponemos pensar la poesía de Aldo Oliva (1927-2000), y fundamentalmente una paradoja constitutiva de su producción: su hermetismo poético, su lenguaje enrarecido y singularizado al extremo, que parecieran alejarlo de la comunicabilidad inmediata y recluirlo en la torre de marfil del artista, conviven sin embargo con una militancia social (teórica y por momentos también efectiva) y un compromiso que se traslucen problemáticamente en sus poemas. El presente trabajo intentará abordar esta paradoja en el cruce entre su producción poética, su figuración o imagen de autor y sus posicionamientos políticos.
\end{abstract}

Palabras clave: Poesía argentina, Simbolismo, Palabra faltante, Tradición.

\begin{abstract}
To George Steiner, modern literature is marked by a rupture that he conceptualizes under the name of "lacking word": in a context where the written word is massified and degraded (because of growing literacy and the proliferation of journals and magazines), the poet confines himself in his ivory tower and self-institutes as literary alchemist, keeper of the pure language, guardian of the ineffable. This figuration of the poet and his role has had various consequences throughout the 20th Century. It is under this trail that we intend to regard the poetry of Aldo Oliva (1927-2000), and within it mainly a paradox that is constitutive of his production: his poetic hermeticism, his rarefied and singularized language, which seem to push him away from immediate communicability and seclude him in the artist's ivory tower, nevertheless coexist with a social activism (theoretical but also effective) and a commitment emerging conflictively in his poems. This article will approach this paradox in the crossroads between Oliva's poetic work, his self-figuration or author's image, and his political stands.
\end{abstract}

Keywords: Argentine Poetry, Symbolism, Lacking word, Tradition. 


\title{
La PALABRa FALtante
}

\author{
Solo el conjuro de la palabra \\ danzando en el holocausto. \\ Aldo Oliva, "Ecuación"
}

En su libro After Babel, George Steiner imprime sobre la literatura moderna, que a su entender se inicia a finales del siglo XIX, el concepto de "palabra faltante" (lacking word). Si hasta entonces el escritor se había movido con comodidad dentro de los límites de su idioma, y su destreza y su genio se medían por su capacidad e inventiva para utilizar los recursos ya a su alcance, a partir de Mallarmé

\begin{abstract}
La literatura occidental y la consciencia del lenguaje ingresan en una nueva fase. El poeta ya no tiene, o aspira a tener, residencia en la casa de las palabras. Las lenguas que lo aguardan en tanto individuo nacido en la historia, en la sociedad, en las convenciones expresivas de su cultura y su medio particulares, ya no son una piel natural. La lengua establecida es el enemigo. El poeta la encuentra plagada de mentiras. La circulación diaria [daily currency] la ha estancado. Las metáforas antiguas han quedado inertes y las energías numinosas se han secado (1976, pp. 177-178; en todos los casos las traducciones son mías).
\end{abstract}

Ahora el poeta trabajará y se debatirá contra el lenguaje, intentando rescindir o, al menos, debilitar, "las continuidades clásicas de razón y sintaxis, de dirección consciente y forma verbal" (p. 178): "El poema presiona contra los confines de la lengua. No trabaja en el molde del discurso público sino a pesar de él" (p. 181).

Steiner no profundiza en las razones sociales por las que este cambio radical tiene lugar en este momento histórico, si bien su referencia a las "mentiras" de las palabras y a su obsolescencia económica abre una perspectiva que Dobry desarrollará en su libro Orfeo en el quiosco de diarios. Para Dobry, el gesto reactivo (defensivo, lo llama él) de la poesía moderna se debe a la democratización y masificación de la palabra impresa a lo largo del siglo XIX, que, con el importante crecimiento de la alfabetización y las primeras grandes tiradas de libros y de prensa periódica, "empezaba a estar al alcance de casi todo el mundo, a la medida del bolsillo y del entendimiento del burgués" (2007, p. 19). La "imparable circulación de material escrito" (p. 20) llevaba, a los ojos de Mallarmé (pero también encontramos vestigios de esta posición en Verlaine y Gautier, por ejemplo), a una devaluación de la palabra, a una banalización de la literatura, a una desacralización del lenguaje. Es así que estos escritores van a comenzar a pensarse, más o menos conscientemente, como "aristócratas del espíritu", como "alquimistas" que intentan devolver la magia al lenguaje, y se alejan tanto en su obra como en su vida de la cotidianidad mundana de diarios y revistas, para configurar lo que Dobry llama "gremio" y lo que Bourdieu, adelantando el proceso algunos años, entiende en términos de "autonomía del arte". Frente a la simplificación y aplanamiento del lenguaje, su enrarecimiento; frente a la objetividad periodística, la subjetividad lírica; frente al utilitarismo y comunicabilidad, el desinterés y la autorreferencia; frente a la masividad y la consagración del mercado e incluso de las instituciones académicas reconocidas, un selecto grupo de pares, "iniciados", "portadores del secreto" de la poesía o la literatura: este posicionamiento, ligado indefectiblemente al nombre de Mallarmé, ha tenido un legado diverso pero incontestable en la poesía del siglo XX, y en la obra del poeta rosarino Aldo Oliva, en la que nos adentraremos a continuación.

La idea de una "palabra faltante", que por fuera de la cárcel del lenguaje cotidiano podría nombrar el absoluto, el infinito, la belleza, puede servir de clave interpretativa en varios poemas de Oliva, que poseen una complejidad "ontológica" en términos de Steiner, quien vincula la complejidad, o la "dificultad" de la literatura moderna, con este nuevo trabajo del poeta no ya con el lenguaje sino contra él. Hasta entonces la dificultad de un texto podía ser referencial o bien de estilo, pero en cualquier caso, con el estudio y la 
investigación suficientes, podía ser aplanado, reconducido a la transparencia del sentido. Ahora el poeta ataca la misma pretensión del lenguaje de comunicar o transmitir un significado claro y preciso, y por eso la dificultad es de un orden "nuevo, motivado ontológicamente" (1975, p. 178): no atañe ya a la antigüedad o erudición de un texto, o a los ornamentos retóricos, sino a la relación entre lenguaje, sujeto y mundo. De entre estos textos resalta, por su carácter paradigmático, "Balada de la Cárcel de Redes", publicado en $D e$ fascinatione (1997), su segundo libro. ${ }^{1}$

El poema concluye con una invocación a esa palabra faltante y definitiva, una exigencia de que la palabra poética (palabra mágica y alquímica), perdida en la banalidad y utilitarismo del lenguaje cotidiano, se haga efectivamente presente: "que irrumpa, / desde la saña y el oprobio, / (me lo exijo), / la Otra (ola / graneada) palabra; / la secreción sagrada, / en explosión, / del tejido celular / del alma, / pulsión del esplendor: / el certero absoluto" (2016a, p. 148). Antes de llegar a esta estrofa final, el movimiento poemático había trazado un recorrido paradójico desde un pasado preñado de futuro hasta un presente impotente que sólo puede mirar hacia atrás, desencantado. El primer verso del poema dice "Fuegos escritos fueron habidos": el paralelismo fonético entre lo que podríamos llamar los dos hemistiquios del primer verso (de las vocales sólo una los diferencia, y en posición no acentuada) resalta por contraste la relevancia semántica de uno y otro. El primer hemistiquio, "Fuegos escritos", es de una densidad semántica que se va a diseminar a lo largo del poema, instaurando dos isotopías: la imagen del fuego y el tópico de la escritura. "Fueron habidos", en cambio, cumple una función análoga a la que, en La cámara lúcida, Roland Barthes otorga al sintagma "esto ha sido”. Es decir: por un lado es un certificado de presencia, un índice de referencialidad; por el otro, ubica esta presencia en un pasado irrecuperable. ${ }^{2}$

Los fuegos escritos, efectivamente escritos pero en un tiempo pasado (importa poco si ese pasado es efectivamente acaecido o si descansa en una noche mítica), dejaban huellas impresas en la "urdimbre del futuro": la palabra plena, que "hoy" falta, garantizaba una determinada continuidad histórico temporal, una proyección hacia un futuro provisto de sentido. Deshecha esa urdimbre, tenemos la segunda parte del poema: "Ahora,/ ira reflejada en el punzante/ caos del espejo/ retrovisor;/ nave, a la ventura,/ escorada a popa,/ reculando" (Oliva, 2016a, p. 147). La mirada melancólica del poeta que se vuelca hacia el pasado sin saber qué hacer con él (el pleonasmo insiste sobre un retroceso que no es impulso para ir hacia adelante sino impotencia y resignación) puede entenderse como un hito más en el proceso que para Dobry comienza precisamente con el simbolismo francés y que, por las causas aducidas más arriba, va transformando el dominio del poeta en

una provincia remota, rica en prestigiosos monumentos decrépitos, como pirámides medio sepultadas en la arena. Aislado de su pasado y en espera de un futuro que ya caducó, no está en las fronteras de la literatura, sino en el desierto de su propia desazón (2007, p. 19).

El título del poema de Oliva, con su referencia intertextual a la "Balada de la cárcel de Reading" de Oscar Wilde, es sintomático en un doble sentido: primero porque Reading (que, no dejamos de notarlo, significa "lectura") se transforma en "redes", las redes del lenguaje burgués que apresan a la voz poética y le impiden pronunciar la palabra absoluta. Pero, segundo, el poeta no tiene otro modo de nombrar esa red que mediante el recurso intertextual a un poema de la tradición que ya no puede orientarlo (la nave está a la ventura), reduplicando la imposibilidad de escapar. Pero Oliva no es solamente un escriba resignado que juega con los fragmentos y ruinas de un pasado muerto, sino que continúa a la búsqueda de esta "palabra faltante", de esta palabra plena (¿mesiánica?) que, logrando atravesar las redes del lenguaje banal y cotidiano, devolvería el tiempo a su cauce y permitiría recuperar la transmisión y fundar una comunidad.

Esta búsqueda es paradójica, ya que su resultado no depende del sujeto: el advenimiento de la palabra puede ser esperado e incluso invocado, como en este caso; pero no depende de la voluntad. De ahí la extrañeza que genera la expresión (que simplifico a fines analíticos): “que irrumpa la Otra palabra (me lo exijo)”. El subjuntivo, que en tercera persona funciona como imperativo, revierte a la exigencia sobre el propio sujeto, en la única aparición de una marca de primera persona singular en todo el poema. Dicho de otro modo: 
si en un primer momento la exigencia parece recaer sobre el lenguaje, al que se ordena comparecer, luego es el poeta el que, consciente de su fracaso inevitable, intenta obligarse a sí mismo. Un paso más acá de Mallarmé, para quien lo que habla es el lenguaje, Oliva sigue reconociendo la importancia del sujeto pero lo ubica en una posición intermedia, mediúmnica podríamos decir. Si volvemos ahora al primer verso del poema, notamos que la formulación pasiva de un verbo impersonal borra la posibilidad misma de un sujeto agente de la acción. No hay sujeto de la escritura del fuego, de sus huellas "impresas/ en la urdimbre del futuro"; o mejor dicho el poeta es propiamente hablando médium, pasaje en el que se actualiza la escritura. Las acciones de este sujeto, tal y como se presentan en la primera parte del poema, son el sueño y la alucinación, estados intermedios en que el sujeto es receptor pasivo de imágenes sobre las que no tiene control ni voluntad. Este posicionamiento intermedio o ambiguo del sujeto (activo/pasivo, potente/impotente) se mantendrá en tensión hasta los últimos versos. ${ }^{3}$

Ahora bien, ¿qué características tendrá esta palabra futura? Primero, será una palabra redentora que absolverá "la saña y el oprobio" desde la cual surge. Mediante un salto dialéctico que debe tanto a sus lecturas de Marx y Hegel como del romanticismo alemán, con su ansiada "fusión de los extremos: el arte y la vida, la antigüedad sin fechas y la historia contemporánea, la imaginación y la ironía” (Paz, 1990, p. 92), la palabra liberadora que busca Oliva deberá atravesar el terreno cenagoso del escarnio y el sufrimiento. El poema que abre la sección "Huellas", de César en Dyrrachium (1986), contiene una exigencia similar a la de la "Balada...", aunque ya no al sí mismo, sino a una potencia ignota; y también remite el origen de la palabra al abismo del dolor: "Dame/ desconocido Señor del Bestiario,/ la voz traída por encima del vértigo,/ la flor nacida del dolor,/ un esplendor en lo real” (2016a, p. 85). Segundo, la palabra fusionará, en una fulguración inmediata e intuitiva, sujeto y objeto (y aquí la herencia romántica de Oliva es aún más evidente): al mismo tiempo "secreción [...] del alma" y "certero absoluto". En el infinito, otro término caro a Oliva (aunque muchas veces aparece con un tinte irónico, connotando lo infructuoso de la búsqueda), sujeto y objeto se con-funden, o, a la manera hegeliana, reconocen finalmente su mutua identidad.

Sin embargo, en algún punto este es un poema atípico en la producción de Oliva. Si bien, como he intentado mostrar, hay una obsesión por la palabra faltante que retorna insistente en muchos de los poemas, raramente se entiende esta palabra en términos tan definitivos y absolutos como aquí. La "Otra palabra", como él la llama, parece aquí abolir la historia, llevarla a su cumplimiento, según una concepción hegelianomarxista con la que Oliva estaba familiarizado (son conocidos los cursos privados sobre ambos autores que Oliva dictaba en Rosario y Santa Fe, durante la década del '70). En todo caso, no hay en este poema una mención al carácter efímero, fugaz, instantáneo de este contacto con el infinito, como sí lo hay en prácticamente todos los demás textos que giran en torno a una palabra plena pero ausente: desde el "esplendor en lo real" antes mencionado hasta la "lírica punción" ("Pie de página”, 2016a, p. 170) o la "purpuración de la palabra" ("Titirimundi”, p. 128), el absoluto que alcanza la palabra, y que escapa a la "cárcel de redes”, es momentáneo y evanescente, y luego deja paso "a la atroz carcajada/ de la usura de la vida” -“Aldebarán (tango)" (p. 145). Como si, para decirlo con Octavio Paz, la analogía que amalgama y armoniza los opuestos no dejara nunca de ser asediada por la ironía, escisión del sujeto respecto del objeto y respecto de sí mismo, consciencia de la finitud y de la muerte (1990, pp. 109-111). En verdad, podemos decir que es este fracaso de alcanzar el absoluto, o mejor dicho de morar en él, lo que funda la poesía para Oliva. No hay palabra definitiva, ni definitivamente plena ni definitivamente muerta, sino que en la poesía adquieren una dialéctica de muerte y resurrección que el autor metaforiza mediante las imágenes de la ceniza y la derrota (en su homonimia de fracaso y camino); por eso las palabras tienen una "dinastía genésica” ("Al tercer día...”, 2016a, p. 195), se "entenebrecen" ("La caza de la mosca en vuelo", p. 160) y se "extinguen" ("Muere Nerval”, p. 113) tanto como purpuran o explotan, nacen ("La escritura de Severino", p. 115) y mueren (“Adiós en noviembre”, p. 89), también procrean y matan - “Gorriones (albricia secreta)” (p. 127). Acaso ningún poema contenga una referencia tan explícita al carácter ambivalente, contradictorio y dialéctico de la palabra poética como este, 
de Ese General Belgrano y otros poemas (2000): "la palabra, evanescente, geminal, homicida,/ que, a veces, sobresaltándose,/ abisma/ la febril plenitud/ de un Poema” (“Aurora”, p. 246).

Dicho de otro modo: lo que falta no es una palabra (y hay que entender "palabra" en toda su posible extensión sinecdótica: verso, encabalgamiento, poema, cita que fulgura en su actualización repentina) determinada, total, que finalmente nombraría el absoluto de una vez y para siempre; lo que falta es la irrupción intempestiva de una palabra que nombre lo nuevo, lo que hasta ese momento no tenía nombre, que permita que el acontecimiento advenga. “¿Clamaré el saber, bendito,/ que no es de la palabra,/ sino de la purpuración de la palabra,/ de la levitación de su aurora?” ("Horóscopo", p. 181). Y esta irrupción está indefectiblemente destinada a faltar, ya que es por definición inapresable. Habría así un movimiento que está detrás de las palabras, que las empuja y las hace aflorar, pero del cual las palabras mismas no son sino su máscara pútrida: "Ah, poema, tus palabras / callan menos que las fuentes, / ocluidas, del poema", dice la voz poética ("Balada de la Cárcel de Redes", p. 148); y Noemí Ulla recuerda que para Oliva "la poesía estaba siempre más allá de lo alcanzado en el poema escrito" (cit. en Aguirre, 2006, p. 23). La poesía de Oliva insiste obsesivamente en el acto de nombrar como acto posterior, necesario para apresar el acontecimiento (o el objeto aún-sinnombre) pero que al mismo tiempo lo petrifica: "¿Llamaremos caballo/ al sismo alucinado/ que halan los lémures,/ al vórtice feral que bate en tierra?” ("Masaje”, 2016a, p. 164). La potencia de la poesía, de la metáfora o de la imagen, es la capacidad extrañificante de nombrar por primera vez, de aprehender el acontecimiento en su surgimiento, antes de que cristalice en la palabra: “...el mar/ (esa loca esmeralda/ que un sueño llamó Adriático/ y la Galia ulterior, 'vagues de rêves')” (“Aliter”, 2016a, p. 78). Aquí la metáfora novedosa se presenta más cercana al objeto al que alude que el nombre convenido y la metáfora gastada. ${ }^{4}$

Es esta potencia inaferrable la que hace que para Oliva, como afirma Ulla, la poesía esté siempre más allá del poema realizado; es esta distancia la que Oliva señala mediante la diferenciación entre el poema y sus "fuentes ocluidas", o entre la palabra y su nacimiento: "Escribo, con palabras, / un nacimiento de palabras:/ ese sarcasmo" ("La jornada en el 'Ehret”, p. 207). Pero esta misma imposibilidad lleva a que la poesía se done hacia el futuro, que los poemas se respondan con nuevos poemas. Como afirma Oliva en una entrevista de 1993 ,

Pareciera que los más grandes establecen siempre una grandeza que deja un déficit de silencio [...] Eso que queda por decir es lo que van haciendo los poetas, y lo que instaura una historia de la poesía en el buen sentido de la palabra (Oliva, 2016b, p. 10).

\section{UNA POSICIÓN CONFLICTIVA}

Las complejidades que alcanza en Oliva la noción de "palabra faltante”, tal y como las he descrito, apuntan hacia un posicionamiento frente al lenguaje cercano al que Dobry, como vimos, encuentra en el simbolismo y fundamentalmente en Mallarmé, y que busca mediante la magia y la alquimia del lenguaje una vía de escape frente a la democratización, homogeneización y devaluación de la palabra escrita que tiene lugar a lo largo del siglo XIX, pero con mayor aceleración al acercarse al fin de siècle. Esta aristocracia espiritual, vinculada al malditismo de los grandes poetas simbolistas y pre-simbolistas franceses (Baudelaire, Rimbaud, Lautréamont, Mallarmé, Verlaine), es decir, a la exclusión y a la incomprensión social, en parte voluntariamente buscada, ha seguido una larga trayectoria en la poesía del siglo XX, tanto europea como americana. En el poema "La puerta estrecha", que Oliva publica por primera vez en 1959 en la revista Pausa, leemos: "Los legítimos hijos de mis padres,/ sus cuerpos perfumados flotando sobre el mar,/ jamás verán la última muralla" (2016a, p. 90). En una entrevista que le realizan Martín Prieto y Daniel García Helder en 1988, el autor parece glosar estos versos. "Yo", dice, "me siento un hijo ilegítimo de esta cultura y de este sistema. Tal vez por eso también me sumí en el ámbito marginal de la libertad iracunda"; y ante la pregunta por quiénes serían los hijos legítimos, responde: "Aquellos que flotan sobre el mar. Los que quieren esta cultura" (2016b, p. 6). A lo largo de treinta años, Oliva mantiene una posición enunciativa marginal, ilegítima, dislocada respecto a la cultura, vinculando 
esta posición con la "libertad iracunda" que le permite crear sin la presión de los padres. Es esta relación intempestiva con la cultura la que le permite afirmar, en una breve autobiografía irónica que dejó al momento de morir, que "A los quince años me tropecé con la cultura: no la recuerdo".5

El distanciamiento respecto a la "cultura", término excesivamente amplio y general, obtiene matices más específicos en el rechazo a la academia y el mercado. Oliva, sin abjurar nunca definitivamente, mantuvo siempre una relación ambigua o tensionada con la universidad. Es útil distinguir dos momentos de esta relación: el primero, desde fines de los ' 50 y durante la década del ' 60 , cuando el poeta estudia cansinamente la carrera de Letras y milita en el Movimiento de Liberación Nacional, que tenía un pie firme en el estudiantado rosarino; el segundo, con el retorno democrático del '83, cuando Oliva, ya recibido, ocupará los cargos de de Literatura Argentina II y Literatura Europea II, e incluso será elegido director de la Escuela de Letras en 1991. Como estudiante discutía el anquilosamiento y cristalización de los saberes académicos, y la "utilidad de una carrera universitaria” (García, 2016, p. 16); puede pensarse que había también una cierta competencia, o al menos irreverencia, frente a ese saber académico, como lo demuestra la anécdota contada por García (que no deja de ser una ficcionalización, pero responde a un relato del propio Oliva) según la cual el autor habría preparado el examen final de Literatura Septentrional en un bar junto a Daniel Wagner, emborrachándose hasta el amanecer para luego ir sin dormir a rendir, y aprobar (García, 2016, p. 16-19). El ámbito de discusión y producción del conocimiento, si entendemos la anécdota como un biografema, parece ser el bar, y la universidad, a lo sumo, un espacio de validación cuya utilidad se pone en duda. Esta caracterización, sin embargo, corresponde más a una autopercepción y una actitud díscola frente a la academia que a la circulación real de las personas y los saberes: en efecto, como muestra el ejemplo del MaLeNa la militancia, el bar y la Universidad muchas veces confluían, se solapaban, se continuaban. Profesores como Adolfo Prieto, David Viñas o Ramón Alcalde, en ese momento docentes de la carrera, eran amigos de Oliva, y admirados por él y por el resto de la bohemia rosarina. La revista Pausa, surgida a fines de los '50, no implica tanto un rechazo como una distancia estratégica respecto a la Facultad de Letras. Como señala Roberto Retamoso, ya desde el título la revista exhibe la continuidad y a la vez la no coincidencia respecto a la cátedra de Literatura Iberoamericana, de cuyo seno surge: "el nombre escogido señala el sentido de momento de interrupción e incluso de intervalo en relación con el ritmo propio de la vida universitaria, al que se instaura para posibilitar la producción de esos trabajos. Pausa se concibe así como un complemento del quehacer universitario" (Retamoso, 2004, p. 306).

Otra es la situación cuando Oliva regresa al país: la militancia como la conocía ya no existe, ha sufrido la derrota histórica que significó la última dictadura militar -también, podría pensarse, ha terminado la juventud en la que el poeta extenuaba bares, "incinerando palabras/ en la urna de las noches" (Oliva, 2016a, p. 142), y esta melancolía a un tiempo personal e histórica se refleja en el poema "Epigraphica del Ehret"-, y la universidad, con todas las resistencias y contramarchas del caso, empieza a sufrir un proceso de profesionalización y especialización académicas muy ajeno al ethos del autor. En este segundo momento las tensiones y rispideces se vuelven más evidentes a pesar (o a causa) de los cargos asumidos por Oliva. El bar, pienso, se transforma para el autor entonces en un espacio de resistencia, donde tiene lugar otra circulación de la palabra, más dialógica o dialéctica, y otra temporalidad, ajena al menos parcialmente a la tiranía de Cronos. Parte del mito de Oliva (sus horarios de consulta en los bares, bajo el imperio del alcohol, y no en la Facultad; su indiferencia frente al costado burocrático y formal de la tarea docente $)^{6}$ tiene su razón de ser en esta relación tirante, contradictoria incluso, respecto a la universidad. En esa posición particular de Oliva en la universidad -dentro de la academia pero con un personaje anti o posacadémico- hay también algo de simbolismo o malditismo: el poeta no encuentra su lugar, ni siquiera en ese "nicho ecológico" que fue y es la universidad para muchos poetas; o, si lo encuentra, es un lugar incómodo tanto para él como para el resto del campo universitario (que encuentra problemática, naturalmente, la falta de constricción de Oliva a las tareas burocráticas: firma de libretas, regularidad en las clases, etc.). De algún modo, para él, la poesía es la verdad y la universidad es lo falso o lo falsificado. ${ }^{7}$ En este contexto, podría pensarse incluso la obra poética de Oliva como escrita desde un doble locus enunciativo en tensión permanente, la Academia (de donde 
provendrían la marcada erudición y el acercamiento riguroso, aunque no reverencial, a la tradición) y el Bar (de donde provendrían la irreverencia y una cierta construcción plural basada en discusiones, intercambios y experiencias compartidas). En el mismo fragmento autobiográfico en el que Oliva afirma no recordar la cultura, confiesa (con un dejo de orgullo) que "desde hace un tiempo corrompo la Academia". Mediante esta inversión axiológica del verbo el autor define bastante bien su relación con la academia tal y como él la entendía. ${ }^{8}$

Respecto al mercado, me interesa detenerme en un poema de Ese General Belgrano..., justamente llamado "Mercado de poesía". Este mercado tan particular en el que se intercambian no ya bienes o servicios en un sentido tradicional, sino poemas, parece obedecer sin embargo a la lógica capitalista que abstrae de las mercancías su valor de cambio para poder conmensurarlas. Los poemas se vuelven así "vacua desdicha palabrera" (2016a, p. 230), genéricos, exentos de toda búsqueda existencial, de todo contacto con "la saña y el oprobio" (este poema menciona directamente la "muerte") para ingresar en un superficial juego social en el que está en juego la "torva apetencia del triunfo". Frente a esto "mi voz [afirma el poema], soterránea/ siempre estará ausente/ de tu escarceo de sombras,/ de los solapados mimos/ con que finges el deseo" (p. 230).

Este rechazo del mundo burgués y sus instituciones representativas (con las que sin embargo no se puede cortar definitivamente) llevaba, en la Francia de mediados del siglo XIX, a alianzas transitorias e inestables entre el grupo de poetas y escritores que mencionara anteriormente, y el "pueblo" y lo que Bourdieu llama "segunda bohemia", compuesta de "intelectuales proletaroides" o "lúmpenes" (1995, p. 92-93); el vínculo entre Baudelaire y Champfleury, tal y como lo analiza el sociólogo francés, sería una prueba de esto. En el caso de Oliva, esta cercanía, además de estar comprobada empíricamente, tiene su justificación en su militancia y su adhesión teórica al marxismo. Secretario de Ramón Alcalde durante su breve gestión al frente del Ministerio de Educación de la Provincia de Santa Fe (mientras perduró la confianza de la "nueva izquierda" en el gobierno de Frondizi), luego participará, entre el '60 y el '66, del MaLeNa (Movimiento de Liberación Nacional), agrupación política nucleada en torno a Ismael Viñas, Susana Fiorito y el propio Alcalde. En esos años integrará también el comité editor de El arremangado brazo, revista que, además de aportar trabajos de crítica literaria y social fuertemente influidos por Contorno, y de insertarse en polémicas intelectuales de la época, tiene en sus dos números una sección en la que se entrevista a trabajadores, dándole la voz a ese otro “soslayado por quienes nombran y deciden lo que importa respecto de Rosario" (Gerbaudo, 2009, p. 87) y exhibiendo crudamente "las condiciones deplorables de trabajo, el sistema corrupto que legitima la situación existente, la falta de organización gremial, la desatención del Estado, la necesidad de un acceso igualitario a la educación" (p. 88). ${ }^{9}$

Este breve repaso por la militancia y las preocupaciones teóricas de Oliva permite visualizar una paradoja que, a mi entender, condiciona su producción poética y lo aleja (al menos parcialmente) de la propuesta mallarmeana y de las posturas más elitistas del "arte por el arte”. Porque, ¿cómo conjugar en la misma obra un hermetismo excluyente y un compromiso social? ¿Deben ser considerados como ámbitos tajantemente separados, sin posibilidad de conexión? ¿Qué concepción de la literatura permitiría el encuentro entre ambos órdenes? ¿Qué concepción de la sociedad? Son estas preguntas las que intentaré, no responder, sino profundizar en el siguiente apartado.

\section{Palabra y MUNDO, PALABRa Y TRADición}

Está claro que Oliva no hace poesía militante, ni panfletaria, ni social en un sentido tradicional. Pero eso no lo lleva a profesar un individualismo elitista, una cerrazón en sí mismo: como afirma al comienzo de un análisis sobre el poema "Recogimiento" de Baudelaire, semejante postura implicaría una ilusoriedad: "pensar que el sujeto está estructurado en sí mismo y no por la relación intercambiable con otros” (2000, p. 11). Oliva dice ilusoriedad, nosotros podríamos decir ideología: respuesta a una determinada coyuntura económicosocial que, al mismo tiempo que da cuenta de ella, distorsiona o invierte sus términos. Dicho de otro modo, 
la "soledad de la palabra lírica" de la que habla Adorno obedece a una doble constricción social: por un lado está "predibujada por la sociedad individualista y finalmente atomística" (2003, p. 54), y por otro lado su propia contraposición a la sociedad, la exigencia de que se libere de la utilidad y de la comunicación, es en sí misma una exigencia social, "la protesta contra una situación social que cada individuo experimenta como hostil, ajena, fría, opresivo-depresiva, situación que se imprime negativamente en la formación lírica” (p. 56). Según el filósofo alemán, la autonomía y la originalidad de la poesía, su "distanciación respecto a la mera existencia”, es un criterio de la falsedad y maldad de esta. Desde este punto de vista el espíritu lírico no es un genio absoluto y transhistórico, sino una reacción contra la cosificación del mundo y el dominio de las mercancías sobre los hombres.

Se entiende así por qué Oliva sí hace poesía social: simplemente porque es imposible no hacerla, porque toda poesía, por hermética que sea, por subjetiva o autorreferencial, es inevitablemente colectiva, parte desde y se dirige hacia un trasfondo social, ya sea para ratificarlo, señalar sus contradicciones o contravenirlo. Como señala Adorno, el medio de esta motivación social

es el lenguaje. La paradoja específica de la formación lírica, la subjetividad que se transmuta en objetividad, está ligada a esa preeminencia del lenguaje en la lírica [...] Pues la lengua es ella misma algo doble. Mediante sus configuraciones, se conforma totalmente a las mociones subjetivas [...] Pero a pesar de eso la lengua sigue siendo el medio de los conceptos, aquello que produce la inalienable relación a lo general y a la sociedad (p. 60).

Pero también se entiende por qué su militancia y su posicionamiento político no podían desembocar en una poesía transparente, coloquial, "cercana” al pueblo. El anhelo de un mundo nuevo, no opresivo, no instrumental, libre y creativo, no puede ingresar en la producción poética en un lenguaje opresivo, banal, estereotipado. Si se propone una vida (o al menos un espacio vital) ajena al reino de la utilidad, al reino de los medios y los fines, es al menos problemático hacerlo mediante un lenguaje que se somete voluntariamente a ese reino, garantizando la comunicación inmediata mediante la transparencia y la claridad de las ideas.

La "palabra faltante" se carga así de un contenido político. Falta una palabra para designar un mundo o un aspecto del mundo que aún no se conoce, pero este aspecto no se conoce porque no existe palabra para nombrarlo. Atrincherarse en el lenguaje conocido (en las palabras, las expresiones, los giros sintácticos, los recursos retóricos consabidos y repetitivos), no forzarlo a ir más allá de sí mismo, implica una afirmación tautológica del mundo existente, la aceptación resignada de una realidad que, en definitiva, no es sino una imposición. ${ }^{10}$ Esta relación dialéctica entre lenguaje y mundo implica la constante transformación mutua de ambos términos, y los obliga a salir permanentemente de sí mismos: la realidad asedia el lenguaje en busca de un nombre, el lenguaje ilumina zonas de la realidad previamente inexploradas. Así, podemos plantear una dislocación de la contraposición que encontrábamos al principio: la poesía de Oliva no opone lo aristocrático o elitista a lo popular, el hermetismo a la claridad "para las masas", sino la tautología, la repetición, la reproducción a la novedad absoluta, a la explosión radical de la palabra en busca de un lector que retome y continúe el movimiento (transformándose así en escritor). Esta contraposición, ya analizada en la "Balada en la cárcel de Redes", insiste en el poema "En el teatro", de Ese General Belgrano..., desde una mirada resignada: "Siento que ya me sumergí/ en el espectáculo:/ que lo que será, ya fue/ en los carteles publicitarios; q que anticipé, en presente,/ la banalidad de una vigencia/ de ansiosa y doméstica espera.// No pretendo abolir,/ con lánguida comodidad/ la explosión radical del futuro inmediato.// Pero ya estoy en el teatro" (2016a, p. 209). El espacio del teatro, asociado aquí directamente a la publicidad y el espectáculo (con la sumisión y pasividad del público, impotente para cambiar aquello que se le presenta), es el espacio de la repetición, del eterno retorno de lo mismo. Al final de la charla sobre Baudelaire en la que analiza "Recogimiento", Oliva interpela al auditorio retomando la misma distinción en otros términos, y ubicándola como condición de posibilidad (o imposibilidad) del movimiento poético, es decir, de la "historia de la poesía en el buen sentido de la palabra": "Y también faltan los poemas de ustedes. Y faltan los poemas sucesivos. ¿Y esto se termina o no se termina? [...] Con respecto a si ese movimiento se podrá detener, depende de que seamos 
débiles o complacientes o saboteadores" (2000, p. 17). Desde una mirada acaso más optimista -la charla tuvo lugar en 1996, mientras que los poemas de Ese General Belgrano..., posteriores, están cargados "de negrura saturnal y enfrentamiento epicúreo con la muerte” (García, 2016, p. 50)-, Oliva invita aquí a sus oyentes a ser "saboteadores", a que la labor poética o crítico-poética sea productiva y no reproductiva, a que el acercamiento a la tradición poética no sea meramente receptivo sino que encuentre en su falta (eso que falta decir) el origen del propio deseo escriturario.

Este es un modo de comprender la relación que la poesía de Oliva mantiene, o pretende mantener, con la sociedad y con sus lectores u oyentes; pero al introducir la tradición (lo que es inevitable al hablar de una poesía marcadamente intertextual, y que trabaja con diferentes estratos de la lengua) la ecuación se complica. Y es que, en principio, es contradictorio recurrir a la tradición y a la historia cuando de lo que se trata, una y otra vez, es de la novedad, de la irrupción del acontecimiento, del futuro incalculable. La serie de la "Epigráfica del Ehret", compuesta de cuatro textos numerados y una coda (la serie, publicada por primera vez en César en Dyrrachium, reaparece en De fascinatione sin el texto final, que se incluye en otra sección), podría testimoniar esta contradicción: en el primero de estos poemas se configura un sujeto poético melancólico, que mira hacia las ruinas de un pasado irrecuperable (simbolizado por el bar "Ehret", que Oliva frecuentaba en los años '60); los poemas siguientes van preparando una transición hacia un movimiento poético-político que culmina con el advenimiento de lo nuevo, "la sangre que en el viento se levanta" (2016a, p. 104). En este final que se abre nuevamente al acontecimiento se abandonan las palabras ilustres y de larga prosapia, que proliferaban en la serie, para dar lugar a una palabra coloquial y malsonante impensable en los versos anteriores: "mierda". La "Balada..." también parece criticar la fijación mortuoria en el pasado, como aquello que debe ser abolido por la "Otra palabra". Sin embargo, ambos poemas permiten otra lectura de la relación entre pasado y futuro, entre tradición y novedad. La "Balada..." no impugna necesariamente el pasado, sino el pasado desconectado del presente, el pasado aislado y cristalizado, alejado de la vida, el pasado canonizado que solo puede ser venerado pero jamás alcanzado por el deseo. Frente a este pasado (mejor dicho: frente a esta contemplación melancólica del pasado), los "fuegos escritos" están preñados de futuro, según una dialéctica por la cual el pasado condiciona el acontecimiento pero este modifica a aquel. Dicho de otro modo: la novedad no puede provenir de una ruptura con la tradición (en esto Oliva se distancia conscientemente de las vanguardias más radicales de comienzos de siglo XX), sino, más cerca de Pound y de Eliot, de un trabajo creativo y deseante con ella. Lejos tanto de la negación rebelde como de la contemplación reverencial, Oliva encuentra en la Historia (en la Historia a secas, pero también en la Historia del arte o de la literatura) las promesas del futuro, los puntos que se iluminarán al contacto de su propia producción. La "Epigráfica..." apunta en la misma dirección. Por un lado, los versos finales no solamente contienen un elemento léxico disruptivo y contrastante, sino también una referencia intertextual a Hamlet, que venía acompañando el recorrido poético desde el segundo texto de la serie. Los versos finales son: "Mierda de persuasión,/ mierda de olvido./ Bebamos, Hamlet,/ la sangre que en el viento se levanta". Por otro lado, formalmente los versos retoman, al tiempo que transforman, un metro extendido en la poesía culta en lengua castellana: el endecasílabo. El verso final es propiamente un endecasílabo, pero los anteriores que contienen el exabrupto léxico también pueden leerse como un endecasílabo descompuesto, desligado por su cesura (en los poemas anteriores de la serie, y en este mismo, proliferan los endecasílabos y sus transformaciones, por lo que el impulso métrico se sostiene de forma muy notoria). Así la "disonancia semántica en los contrastes de estilo" (expresión que utiliza el propio Oliva al analizar un poema de Borges), ${ }^{11}$ marcada aquí por la introducción de un término, repetido además, fuertemente contrastante con el contexto, se encuentra cobijada por una estructura formal que vuelve a articular los lazos con la tradición. Y de hecho la impresión que produce el final del poema no es de ruptura absoluta, sino de la intensificación de algo que venía siendo oscuramente preparado. ${ }^{12}$

"Instante se alzará/ en la derrota de esta letra/ en que cante el legado/ del esplendor futuro". Estos versos, que Oliva escribe en "De fascinatione", el poema que da nombre a su segundo libro (2016a, p. 153), tematizan la relación entre pasado, presente y futuro que estoy queriendo desarrollar. Referir a la "derrota” de esta letra es 
aludir a su fracaso pero también a su camino (su derrotero), a su movimiento póstumo incesante, a su eventual resurrección. La palabra muerta, definitivamente anclada al pasado (a su canonización cristalizadora), puede arrojar su ropaje mortuorio y volver a encenderse, irradiar nuevos sentidos, abrir nuevas perspectivas; es por eso que la imagen de la derrota está emparentada, en la poesía de Oliva, con la de las cenizas, rescoldo siempre pasible de ser revivido, no tal como fue, sino como será en contacto con el futuro. Pensar el legado del futuro implica pensar un tiempo histórico en un sentido benjaminiano, no lineal ni cronológico sino dialéctico, en una articulación siempre renovada de tradición y ruptura, pasado y novedad, lectura y deseo. Es esto lo que hace Oliva en tantos de sus poemas, empezando por el que da comienzo a su primer libro: "Diégesis a Lucano" es una reescritura fragmentaria del "Libro VI" de la Farsalia, en la cual, sin rigidez filológica pero siendo respetuoso del original, carga el texto de Lucano de una actualidad y de connotaciones políticas acuciantes simplemente incluyendo una fecha, 1976. Una segunda parte de este poema, llamada “Aliter", configura una especie de respuesta del propio Oliva a Lucano, sorteando mediante la magia de la escritura dos milenios y un océano. Allí el autor rosarino entiende metafóricamente la batalla de Dyrrachium, donde Pompeyo pudo derrotar a César y decidió no hacerlo por no "profanar con mis tropas/ los templos de mi patria y desatar la lucha/ en el centro del Foro...” (Oliva, 2016a, p. 75), como el punto de partida del desarrollo capitalista de Occidente, ya que a partir de allí "una incierta moneda/ congregó al oro cándido/ que alumbraba el espacio,/ legisló entre las sombras/ los bienes de la tierra,/ roló en ríos de sangre,/ trocó en precio la muerte/ y restalló en los signos que rigieron la vida" (p. 77). Lo interesante es que Lucano no podía saber esto, y sin embargo “...aquella boca/ sometida al poema lo sabía” (p.76). El poema, en su potencia profética (nuevamente tenemos aquí una variante del médium), trasciende al hombre de carne y hueso que lo escribe, y se transforma con cada nueva lectura, con cada nueva actualización. Lo mismo, ya no referido (solamente) a la escritura sino a las consecuencias imprevisibles de los actos de los hombres, afirma Belgrano al momento de su muerte: “...eso, que afirmamos vida,/ es ser el contemporáneo del futuro: esa oculta furia/ asediando lo desconocido/ llamado presente" ("Ese General Belgrano", p. 289). Del poema inaugural de su primer libro al que cierra el último, la escritura y el accionar de los hombres relanzan una y otra vez los dados del destino, dando lugar a nuevas configuraciones de pasado, presente y futuro. ${ }^{13}$

\section{Entre Ezra Pound y Walter Benjamin. Conclusión}

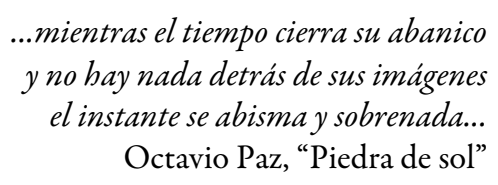

Hasta aquí he intentado analizar el modo en que la obra de Oliva intenta conjugar dos polos en apariencia irreconciliables: una poesía hermética, erudita, intertextual, y una determinada sensibilidad social y un compromiso político que atraviesa varios de los textos - para Sergio Raimondi, la obra de Oliva debe ser leída tanto en términos de "metafísica, aura e infinito" como de "historia, marxismo y estricta coyuntura" (2007, p. 101). Conjugar estos dos polos, o acaso habría que decir, mantenerlos en tensión. Si hemos de creer a la ficcionalización que hace Ulla en su novela Los que esperan el alba. Oliva ya reconocía este problema en la década del '60, al afirmar que él hace poesía "de lo presente, de lo que se está viviendo [...] Pero yo todavía me manejo en un plano muy abstracto, muy hermético" $(1967$, p. 77$) .{ }^{14}$ En cualquier caso, es indudable que hay en esta producción un marcado componente luctuoso (que, como señala Dobry mediante la imagen de las pirámides sepultadas en la arena, recorre buena parte de la poesía moderna), una melancólica mirada a las ruinas del pasado que ya no puede hacer nada con ellas más que mezclarlas indefinida y, en un punto, caprichosamente. Esta mirada desencantada podría además vincularse, siguiendo una hipótesis de Raimondi, con la disociación absoluta que Oliva encontraría entre poesía y política en su época: hablando de la reescritura de la Farsalia, Raimondi señala la distancia insalvable entre el poema de Lucano, "en su 
momento un hecho político en sí mismo", y el de Oliva, que partiría de la constatación de que la posibilidad de la intervención política está clausurada, "no simplemente por las características de gobierno de la junta militar de turno", sino porque en la historia argentina "ya no están dadas las circunstancias para la existencia de ese poeta capaz de intervenir en los debates públicos [...] El poeta ya no puede intervenir en un ágora inexistente" (2007, p. 112). Así se explicaría la presencia de Lucano como único interlocutor de "Aliter", y la dicción anacrónica que respeta el orden sintáctico latino.

Sin negar esta lectura pesimista, "saturnal" de la poesía de Oliva, mi trabajo apuntó a recuperar otro recorrido posible, no excluyente, según el cual la vuelta hacia el pasado no sería completamente nostálgica, sino tensionada por el acontecimiento futuro, y la intervención no sería pública y en el ágora pero tampoco imposible, sino estocástica e imprevisible. El interés recurrente de Oliva por Lucrecio y por el clinamen epicúreo, esa desviación inesperada de los átomos que perturba el equilibrio entrópico del sistema, que durante mucho tiempo fuera considerado (entre otros por Marx) una metáfora de la libertad del espíritu (García, 2016, p. 37), puede servir para pensar el carácter disruptivo que aquel otorgaba a la poesía. En la desviación respecto del canon, en las fisuras de un pasado de apariencia monolítica, en el contacto deseante con la tradición, es que la poesía de Oliva puede encontrar su lugar. Es como si el poeta se moviera entre la concepción de la historia que anima la obra de Pound en la lectura agambeniana, y la que se desprende de las Tesis sobre el concepto de historia, de Walter Benjamin. Según la primera, la tradición

religiosa, filosófica y poética no es convocada, como hasta entonces había ocurrido, por su capacidad de nutrir y orientar la vida y la palabra de los hombres sino, por el contrario, precisamente porque parece haber perdido esa capacidad. Lo que se exhibe es precisamente esa pérdida (Agamben, 2018, p. 11).

En la famosa tesis IX de Benjamin, el Ángel de la Historia parece en una situación semejante a la de Pound, incapaz de volver a la vida las ruinas del pasado porque es arrastrado por el viento del progreso; pero en las otras tesis (en las cuales critica fuertemente la idea de progreso y la concepción correlativa del tiempo como algo homogéneo y vacío) el filósofo alemán señala el carácter constructivo del acercamiento del historiador materialista al pasado: el verdadero historiador no pretende conocer el pasado "tal y como ocurrió", sino que establece una relación única con él en la cual tanto aquel como este se ven transformados. Para Benjamin, se sabe, todo pasado lleva un índice que lo remite a la redención (es decir, que permite salvarlo de la acumulación ruinosa que contempla el Ángel de la Historia); esta redención implica arrancar el pasado del continuum homogéneo de la historia para hacerlo entrar en un contacto incandescente con el tiempo-ahora (Jetztzeit; ¿podríamos decir, con Oliva, "instante"?), que implica un peligro porque la imagen histórica "relampaguea fugazmente" y por lo tanto podemos perderla, devolviendo el pasado al conformismo que es herramienta de la clase dominante. En síntesis: cada época debe intentar arrancar de nuevo la tradición al continuum que la mortifica y la aplana, a la historia, o mejor, el historicismo que confía en un curso lineal y progresivo de la historia y concluye siempre en una afirmación del orden existente, del statu quo, ya que ve el presente como un resultado necesario de la concatenación de los hechos pretéritos. Frente a esto, el historiador materialista debe "extraer" los hechos, las obras, el patrimonio histórico, de esa periodicidad incontestable, para encontrar allí los silencios, las potencialidades obturadas, las promesas incumplidas, aquello del pasado que espera ser salvado y articulado en el presente. ¿No es esto, si bien con propósitos diferentes, lo que hace Oliva al acercarse a la tradición poética y artística occidental? ¿No extrae, por ejemplo, la Farsalia de su transmisión (tradición) académica, para devolverle un índice de actualidad que lo contacta inmediatamente con el presente (argentino y mundial)? ¿No intenta así arrancar este texto de la canonización mortuoria que lo convierte en un clásico y classis, nos recuerda Roberto García, "quiere decir ejército" (2016, p. 26)-, con un sentido ya determinado e indiscutible? ¿No hace del instante, en lugar de un presente efímero e intangible, una "constelación saturada de tensiones" (Benjamin, 2009, p. 50) entre presente y pasado? ¿No se explicaría así la paradoja de que un poeta que trabaja marcadamente con el intertexto y con la cita afirme al mismo tiempo, si hemos de creerle a Ulla, que en sus poemas habla "de lo presente, de lo que se está viviendo"? 
Esta actitud, entre resignada por la impotencia social de la poesía y esperanzada por sus derroteros inesperados, puede encontrarse en la obra de Oliva, en su forma de relacionarse con sus lecturas, y constituye un acercamiento a su propia producción. Ni poesía para las masas, poesía transparente para el pueblo, o que ilustre verdades histórico-políticas provenientes de otro ámbito; ni poesía hermética, construida deliberadamente para excluir a un sector social que no estaría a la altura espiritual para apreciar las sutilezas de la belleza y el arte. En todo caso poesía exigente, sí, pero que no pide ser venerada sino continuada, trabajada, discutida, vuelta a poner en movimiento al calor de nuevas lecturas, nuevos acontecimientos, nuevos presentes. Poesía, además, que no pretende adecuarse a un público preconstituido, sea popular o elitista (y de ahí también la "marginalidad" de Oliva, su "voluntario anacronismo", su "fracaso", que la crítica ha señalado insistentemente), sino que espera el encuentro incalculable con un lector futuro.

Así como comencé con el análisis del poema "Balada de la Cárcel de Redes", quisiera terminar con el de otro poema, que ya desde el título es una invitación a pensar los problemas que he venido planteando: "Panfleto". ${ }^{15}$ El poema se encuentra en De fascinatione, y por supuesto no es un panfleto, salvo en un sentido irónico y distanciado: no expresa una prédica dogmática y fácilmente apropiable, no ilustra verdad extrínseca alguna, ni cede a las exigencias de fácil comprensión y circulación que un discurso semejante pretende. No puede considerarse un manifiesto (por la complejidad de su lenguaje y por su ubicación, hacia el final del libro), tampoco propaganda política, y su intención polémica, ciertamente existente, se evidencia recién al final del poema, en forma velada y con un destinatario indeterminado: "Cada/ abolición tecnomántica/ no cerrará la boca/ que fulge en su/ esplendor de Sí.// No cegarán, no segarán/ el terror floral del parto/ altivo, solidario/ de la trova" (2016a, p. 187-188). Pero sí hay algo de programático, si es que puede hablarse de un programa del acontecimiento, y de arte poética que implica un posicionamiento político. Ya desde su primera palabra (que es también la última), el poema determina su tema: la trova, que la RAE entiende, en este orden, como "verso", como "composición métrica formada a imitación del método, estilo o consonancia de otra", como "composición métrica escrita generalmente para canto", y como "canción amorosa compuesta o cantada por los trovadores". Más allá de las resonancias trovadorescas, que no deben desdeñarse pero tampoco se desarrollan en el texto, podemos decir, retomando a Girri, que "el motivo es el poema". Pero, como venimos viendo, el poema en tanto producción, en tanto advenimiento al ser, y no en tanto producto o resultado. Y es por eso que, paradójicamente, el canto es también silencio, es iluminación "de" la tiniebla (en el doble sentido del genitivo, subjetivo y objetivo): "Cantar, en las fisuras/ del vacío, quiero llamar/ a la irradiación que/ la tiniebla alumbra;/ su raíz, fulminante,/ emergente, que es/ aún silencio" (p. 187). "Irradiación", "fulminante", "emergente"; "conmociones", "instante", "fogonazo" (en versos anteriores); "quebrante", "fulge", "esplendor", "parto" (en versos posteriores): el problema del poema (y de buena parte de la obra de Oliva) pareciera radicar en dar lugar a ese mero pasaje, a la "purpuración”, que ya no es la nada pero todavía no es el púrpura. Hacia el final del poema, la voz sí se torna asertiva, imperativa incluso, para rechazar a aquellos que querrían ocluir el acontecimiento, "cegarlo" o "segarlo", o predecirlo mediante aboliciones tecnománticas, es decir, adivinaciones técnicas. Precisamente porque el poema es acontecimiento imprevisible es que un panfleto poético no tiene razón de ser, y el carácter programático del texto se deshace a sí mismo.

Pero este carácter prácticamente incomunicable del poema no excluye la posibilidad de una comunidad, de un paradójico contacto entre el poeta y sus lectores: en efecto, el "terror" de la trova es altivo pero solidario. Un poco antes la voz poética había dicho: "Somos millones, elípticos, / en el ritmo futuro de los/ armónicos de la tierra sonora;/ de la aurora que/ quebrante la ausencia” (p. 187). Aquí el poeta se despersonaliza o se pluraliza en un "nosotros" elíptico, tácito, en un doble sentido: porque está obliterado por los discursos y las prácticas establecidas y comprendidas que lo excluyen y lo tachan, pero también porque ese nosotros está proyectado hacia el futuro. Es el poema el que funda comunidad, el que, a partir de su ritmo y su "sonido fundamental" ("la tierra sonora"), despierta una resonancia armónica novedosa. En una entrevista realizada 
en 2018, el hijo de Aldo Oliva, Ángel, también poeta, expresa esta particular potencia in/comunicadora de la poesía al decir que la conmoción que produce

rompe todo tipo de lazo comunicante en el sentido tradicional de la palabra, ¿no? Un mensaje que debe ser claro, comprendido, principalmente tranquilizador [...] esto es al revés, esto va dirigido a la pregunta de: "ípodemos ser otra cosa de lo que fuimos hasta aquí?” Me parece que eso es lo que va expresando la ampliación de la emocionalidad. Finalmente la poesía está en los límites, en las formas más excesivas, límite de las formas posibles de humanidad. Va corriendo el horizonte (Oliva, 2021, p. 291).

Si bien no es forzoso que el hijo defienda las concepciones poéticas del padre, me parece que en este punto coinciden: al "correr el horizonte" y proponer formas nuevas de humanidad, la poesía trabaja contra el reconocimiento tranquilizador de los mensajes comunicativos, reconocimiento que confirmaría las posiciones preestablecidas de sujeto enunciador (poeta) y receptor (público). En cambio, el tipo de contacto que el poema propone, y que aquí es remitido a la ampliación de la emocionalidad, Ángel lo entiende mediante el término "resonancia". La resonancia sería para Ángel el efecto de una voz (un poema) "dentro de tu emocionalidad". Ese punto, o el conjunto de esos puntos de indistinción entre poeta, poema y lector u oyente (entre voz, lenguaje y cuerpo), es lo que, creo, Aldo Oliva nombra al hablar del "ritmo futuro de los/ armónicos de la tierra sonora”.

\section{REFERENCIAS}

Adorno, T. (2003). Discurso sobre lírica y sociedad. En Notas sobre literatura (pp. 49-67). Madrid: Akal. Agamben, G. (2018). Situación de Ezra Pound. En E. Pound, Cantos (pp. 7-16). Madrid: Sexto Piso.

Aguirre, O. (2006). Cronología. Diario de poesía, 76, 13-14, 22-24, 28. Recuperado de: https://ahira.com.ar/revista s/diario-de-poesia/

Benjamin, W. (2009). Sobre el concepto de historia. En La dialéctica en suspenso (pp. 37-82). Santiago de Chile: LOM. Bourdieu, P. (1995). Las reglas del arte. Barcelona: Anagrama.

Crisorio, B. (2017). Aldo Oliva: un fantasma en la poesía argentina. Estudios de Teoría Literaria, 11, 203-216. Recuperado de: https://fh.mdp.edu.ar/revistas/index.php/etl/article/view/1723/2151

Crisorio, B. (2018). Mojones provisorios. RILL, 22, 18-33. Recuperado de: http://filo.unt.edu.ar/insil/rill/

Crisorio, B. (2019). Usos intempestivos del patrimonio histórico y cultural de Occidente en la poesía de Aldo Oliva. Culturas. Debates y perspectivas de un mundo en cambio, 13, 39-55. https://doi.org/10.14409/culturas.v13i13

Dobry, E. (2007). Orfeo en el quiosco de diarios. Buenos Aires: Adriana Hidalgo.

Fondebrider, J. (comp.) (2006). Tres décadas de poesia argentina. 1976-2006. Buenos Aires: Universidad Nacional de Buenos Aires.

García, R. (2016). La ética del futuro. En A. Oliva, Poesía completa (pp. 7-53). Rosario: Editorial Municipal de Rosario.

Gerbaudo, A. (2009). Papeles olvidados en una siesta provinciana. En M. A. Hechim (ed.), Discurso y crítica literaria (pp. 77-111). Santa Fe: Universidad Nacional del Litoral.

Oliva, Aldo (1986). Borges y el ultraísmo. Paradoxa, 1, 57-77.

Oliva, Aldo (2000). Charles Baudelaire. revista endymion, 2.

Oliva, Aldo (2016a). Poesía completa. Rosario: Editorial Municipal de Rosario.

Oliva, Aldo (2016b). Entrevistas 1988-1999. Rosario: Editorial Municipal de Rosario.

Oliva, Ángel (2021). La poesía en los límites. Entrevista realizada por Bruno Crisorio. En Escrituras en voz. Conversaciones sobre literatura argentina (pp. 287-307). La Plata: Publicaciones FaHCE.

Paz, O. (1990). Los hijos del limo. Barcelona: Seix Barral.

Piccoli, H. (s/f). La poética de Aldo Oliva [Lectura realizada el 7 de octubre de 2002, con motivo de la presentación de Una batalla]. Rosario: Sueltos de Revista Mirto. 
Raimondi, S. (2007). La guerra en la Argentina de los setenta según Marco Anneo Lucano (sobre César en Dyrrachium de Aldo Oliva). En Cuadernos Lirico, 3, 101-114.

Retamoso, R. (2004). La revista Pausa: una experiencia de formación y búsqueda en la historia de la literatura de Rosario. En Revista de letras, 9, 303-311.

Shklovski, V. (1978). El arte como artificio. En T. Todorov et al., Teoría de la literatura de los formalistas rusos (pp. 55-70). México: Siglo XXI.

Steiner, G. (1975). After Babel. Aspects of Language and Translation. Oxford: Oxford University Press.

Ulla, N. (1967). Los que esperan el alba. Santa Fe: Dirección General de Cultura.

\section{Notas}

1 Balada de la Cárcel de Redes: "Fuegos escritos fueron habidos. / En un tiempo, / actos de súbita aprehensión, / altos, crípticos, soterrados: / la oropéndola entrando / en la capital del alba; / la omnígera / capital del dolor / fascinada en el virus / de la belleza; el placer / enmascarado. // Algunos lo soñaban. // Otros, / en la socarrona inocencia / de la pudibundia / (digamos, la hojarasca, / triturada, llovida, / del poder), / alucinaban la aventura / planetaria del zarapito. // ¿Qué verdad se incineró / en el núcleo de la verdad? / ¿La lágrima, pendular, / del ojo de Eros / es la inmarcesible / perduración / de la ceniza del Fénix? / Aves caídas en redada / fingidora de cielos; / huellas de fuego / impresas / en la urdimbre del futuro. // Fue en un tiempo. // Ahora, / ira reflejada en el punzante / caos del espejo / retrovisor; / nave, a la ventura, / escorada a popa, / reculando / de la textura del silencio; / filigrana (que nos cubre) / del abismo; / hipóstasis / de las transfiguraciones / de la selva. // Ah, poema, tus palabras / callan menos que las fuentes, / ocluidas, del poema. / El hábito mortal / de vivir / cegó la matriz, / inseminada, de tu altura. / Habitantes de esta / cárcel, invisible, / de redes: que irrumpa, / desde la saña y el oprobio, / (me lo exijo), / la Otra (ola / graneada) palabra; / la secreción sagrada, / en explosión, / del tejido celular / del alma, / pulsión del esplendor: / el certero absoluto" (Oliva, 2016a, pp. 146-148).

2 Por supuesto, Barthes entiende que este índice es una potencia específica de la fotografía, al punto que constituiría su "noema", su "esencia". Pero como señala Clément Rosset, y sin duda el propio Barthes sabía, la fotografía podía ser alterada, trucada o montada ya desde sus orígenes. Por lo tanto, para que el apotegma barthesiano mantenga cierta vigencia, es preciso entender que la fotografía se presenta "como si" fuera un registro inmediato de su referente, del que no se puede dudar; y creo que la misma lógica sigue el verso inicial del poema que analizamos, cuyo carácter tajante e incontestable se enfatiza por la coincidencia métrico-sintáctica.

3 Hay otros dos poemas de De fascinatione en que se repite, casi en los mismos términos, la idea de la "irrupción de la palabra". En "Pie de página" leemos: "Un cosmos, en la palabra,/ de la mutación floral,/ que irrumpa" (2016a, pp. 169-170). En "Ese filoso vino en la garganta": "Nadie sabe lo que sabe/ hasta la explosión de la palabra" (177).

4 La alusión a la ostranenie formalista no es por supuesto casual o caprichosa: para Shklovski, como sin lugar a dudas para Oliva, "El acto de percepción es en arte un fin en sí y debe ser prolongado. El arte es un medio de experimentar el devenir [Oliva hubiera preferido "advenir"] del objeto: lo que ya está realizado" no interesa para el arte" (Shklovski, 1978, p. 60). La diferencia que encuentro es la consciencia en el autor rosarino de que esta potencia desautomatizadora es evanescente en el mismo arte: el arte es el lugar en el que ocurre el advenimiento del objeto (incluso podría pensarse que es este mismo tener lugar), pero no puede custodiarlo, no puede prolongarlo indefinidamente.

5 En Crisorio (2019) intento analizar el vínculo dislocado que Oliva entabla con la cultura, entendiéndola allí como el patrimonio histórico y cultural de Occidente.

6 Es necesario aclarar que en la Facultad e Humanidades de Rosario es usual que los profesores den sus consultas en los bares aledaños. No es solo una característica de la práctica de Oliva sino una dinámica habitual de la vida académica (agradezco al evaluador o evaluadora, cuyo nombre desconozco, por la observación).

7 Agradezco a Edgardo Dobry por estas reflexiones.

8 Agradezco nuevamente al evaluador o evaluadora, quien me hizo ver que las aseveraciones respecto a la relación de Oliva con el espacio académico eran, en la primera versión que envié a la revista, un poco maniqueas y simplistas; y a Roberto García, con quien discutí el tema a partir de esa observación, y me permitió matizar y fundamentalmente complejizar la posición de Oliva al interior de la universidad. La distinción entre la Universidad de los '60, en la que Aldo estudiaba, y la de finales de los ' 80 y los ' 90 en la que se desempeña como profesor y director de la carrera, así como los modos diferentes en que Oliva articulaba ese espacio con el bar, son ideas de Roberto a las que espero haber sido fiel. De cualquier modo, la ecuación bar/universidad en el caso de Oliva merece un abordaje más amplio que espero poder desarrollar en un próximo trabajo.

9 En la novela Los que esperan el alba, Noemí Ulla recuerda la experiencia de esta revista, y en una charla con Diego Raigal (evidente alter-ego de Aldo Oliva) dice: "Un reportaje hecho a un obrero, las respuestas que ese tipo da, descubren cosas 
que la gente prefiere silenciar, porque ya no se trata de la 'cultura universal' sino del país, de la situación del país. Y una revista que intente el alumbramiento en ese sentido, va al muere o a la marginación” (1967, p. 78).

10 Cf. "El enigma sedente del bar" (Oliva 2016a, p. 192). En verdad, en este poema lo impuesto no es la realidad sino lo "Real". Recuperando desarrollos lacanianos, Oliva otorga a esta palabra una ambigüedad y una complejidad que exceden el alcance del presente trabajo. Baste decir aquí que por momentos lo real (o la realidad, en otros poemas) es lo convenido, lo consensuado, una determinada visión del mundo y de la sociedad que se presenta como evidente e indiscutible; y por momentos es aquello que horada ese consenso, abriendo la puerta a lo imposible o lo impensable (podríamos llamarlo también acontecimiento). El poema "Crónica de un desalojo", de Ese General Belgrano..., retoma esta ambigüedad o este doble sentido al señalar que en el sueño un timbre "estremece como lo real lo real” (2016a, p. 221).

11 Ver Oliva (1986, p. 65).

12 En Crisorio (2018), intento un análisis exhaustivo de la "Epigráfica del Ehret" teniendo en cuenta estas particularidades léxicas y formales que aquí simplemente esbozo.

13 En otro lugar (Crisorio, 2017) he analizado esta imbricación de presente, pasado y futuro apoyado en los conceptos de "contemporáneo" (Agamben) y “anacronismo" (Didi-Huberman): Oliva recurriría a la tradición como un modo de hendir el presente, de separarlo de sí mismo y mostrar sus complejidades internas, las diversas tramas que lo componen, como un modo de adentrarse en las profundidades de un mar que, como dice en la entrevista citada, otros conocen solamente en su superficie.

14 Por lo demás, la narradora (alter-ego de Ulla) da testimonio más adelante de las discusiones en torno a la relación entre poesía y sociedad: "todo lo que dice el poema - sea cine u otra forma de arte- no es ninguna fantasmagoría. Es la realidad que vive el poeta. ¿Arte para el pueblo? ¿Pueblo para el arte? Viejo conflicto. Los que hacen el arte, el cine, la literatura, tratan de resolverlo" (p. 158).

15 Panfleto: "Trovas selectas / en las conmociones / de la constelación del instante; / en el fogonazo, tácito, que / aún no es. / Su luminosa / incisión sobre el ojo, / opacado, del mundo. // Cantar, en las fisuras / del vacío, quiero llamar / a la irradiación que / la tiniebla alumbra; su raíz, fulminante, / emergente, que es / aún silencio. / Somos millones, elípticos, / en el ritmo futuro de los / armónicos de la tierra sonora; / de la aurora que / quebrante la ausencia. // Vamos apenas. / Cada / abolición tecnomántica / no cerrará la boca / que fulge en su / esplendor de Sí. / No cegarán, no segarán / el terror floral del parto / altivo, solidario / de la trova." (2016a, p. 187-188). 